\title{
Miniaturized Electrochemical Biosensor based on Whole-Cell for Heavy Metal Ions Detection in Water
}

\author{
Emanuele Luigi Sciuto ${ }^{1}$, Salvatore Petralia ${ }^{2}$, Janroelof van der $\mathrm{Meer}^{3}$, and Sabrina Conoci ${ }^{4}$ \\ ${ }^{1}$ Azienda Ospedaliero Universitaria Policlinico "G.Rodolico - San Marco" \\ ${ }^{2}$ University of Catania \\ ${ }^{3}$ University of Lausanne \\ ${ }^{4}$ University of Messina
}

September 21, 2020

\begin{abstract}
The heavy metals pollution represents one of the important issues in the environmental field since they are involved in many pathologies from cancer, neurodegenerative and metabolic diseases. We propose an innovative portable biosensor for the determination of traces of trivalent Arsenic (AsIII) and bivalent mercury (HgII) in water. The system implements a strategy combining two advanced sensing modules consisting in (a) a whole cell based on engineered Escherichia coli as selective sensing element towards the metals and (b) an electrochemical miniaturised silicon device with three microelectrodes and a portable reading system. The sensing mechanism relies on the selective recognition from the bacterium of given metals producing the 4-aminophenol (PAP) redox active mediator detected through a cyclic voltammetry analysis. The miniaturized biosensor is able to operate a portable, robust and high-sensitivity detection of AsIII with a sensitivity of $0.122 \mu \mathrm{A} p \mathrm{pb}-1$, LoD of $1.5 \mathrm{ppb}$ and a LoQ of $5 \mathrm{ppb}$. The LoD value is one order of magnitude below of the value indicated to WHO to be dangerous (10 $\mu \mathrm{g} / \mathrm{L})$. The system was proved to be fully versatile being effective in the detection of $\mathrm{Hg}$ (II) as well. A first study on $\mathrm{Hg}$ (II) showed sensitivity value of $2.11 \mu \mathrm{A} / \mathrm{ppb}$ a LOD value of $0.1 \mathrm{ppb}$ and LoQ value of $0.34 \mathrm{ppb}$. Also in this case, the detected LOD was ten time lower than that indicated by WHO $(1 \mathrm{ppb})$. These results pave the way for advanced sensing strategies suitable for the environmental monitoring and the public safety.
\end{abstract}

\section{Keywords}

Trivalent arsenic; Divalent Hg; water monitoring; whole-cell-based biosensing; electrochemical detection; silicon technology.

\section{Introduction}

The heavy metals pollution, as consequence of the industrial progress and the human activities, is one of the important issues in the environmental field representing an appealing research. Heavy metals are involved in many pathologies from cancer, neurodegenerative and metabolic diseases. One of the most contaminated natural resource is water, since metals are often spilled in soils through the industrial and consumer wastes and accumulate in streams, lakes, rivers and water intended for direct consumption bringing a series of implications for the human safety (Masindi, Muedi, 2018; Verma, Dwivedi, 2013). The water poisoning by arsenic is one of the most studied subjects in this field. Arsenic is a natural metalloid element diffused at different levels, from soil to water and air. Within this distribution, it can react with oxygen or other molecules producing various inorganic compounds, among which the toxic arsenite (AsIII) (ATSDR, 2007). About 140 million people in 50 countries are under the risk to use drinking, food preparation and irrigation water that is poisoned by AsIII at levels above the World Health Organization (WHO) provisional guideline value of $10 \mu \mathrm{g} / \mathrm{L}$, becoming very dangerous for human safety (World Health Organization, 2020; Ravenscroft 
et al., 2009). When high concentrations of AsIII are present, the accumulation inside the human organism by ingestion causes different effects from simple skin lesions to more dangerous systemic disorders. Prolonged exposures to AsIII, in fact, have been linked to cardiovascular diseases, diabetes and liver, prostate and bladder cancer, while other studies suggest a relationship with neurological effects and reproductive organs (Hong, Song, Chung, 2014). Moreover, it seems to influence the cognitive development and the incidence of youthful deaths (Mandal, Suzuki, 2002).

Therefore, considering the arsenic toxicity it is extremely important the availability of effective sensing technologies able to detect and quantify AsIII in water. Unfortunately, many of the available detection systems have several limitations mainly due to the complexity of the analysis. Spectrometric (CV-AAS, AEF, CV-AFS), chromatographic and potentiometric technologies even if they are the advantages to be consolidate methods with low detection limits (LoD) of about $1 \mu \mathrm{gL}-1$ or 1 part per billion (ppb) and a wide range of linearity in the determination of arsenic, however, present some drawbacks in terms of time/cost consuming, long procedure, expensive reagents, the need for a sample pre-concentration, lab constraints referred to the bulky instrumentations and the high trained personnel required to perform the analysis (United States Environmental Protection Agency Office of Water, 1999; Yu, Wang, 2013; Bose, Rahman, Alamgir, 2011).

In this context, recently ultrasensitive method for dual-mode detection of arsenic by colorimetric and surfaceenhanced Raman SERS using glutathione functionalized Au-nanoparticles has been described reaching LoD of $0.14 \mathrm{ppb}$ (Lia et al., 2020). Colorimetric assay on Paper-based microfluidic device are has been developed allowing a rapid and low-cost detection through a direct observation of a colour change induced by the reaction of arsenic with specific dyes (Morita, Kaneko, 2006; Martinez et al., 2010). This detection method is performed on paper strips or microfluidic system so that the reagents are automatically mixed and give a colorimetric signal. However, the main drawback of the procedure is the specificity, since other molecules can cross-react with the sensing dyes (phosphates and silicates, for example, compete to react with molybdenum blue) giving a false positive and the sensitivity reaching a $\mathrm{LoD}$ value of $10 \mathrm{ppb}$ (Lace et al., 2019; Yogarajah, Tsai, 2015) .

Among the heavy metals pollution, also $\mathrm{Hg}$ represent a very dangerous analyte. Actually, in its divalent inorganic form (HgII), it is frequently spilled in water as waste of industrial activities and accumulates over $1 \mathrm{ppb}$ (defined by the WHO as the threshold value for human safety) becoming toxic and bringing a high risk to contract severe diseases as neurological disturbances, skin rash and kidney failure. Therefore, a punctual quantification of mercury traces in water is necessary and is, usually, performed by combined gas/liquid chromatographic-spectrometric methods (GC-AFS, HPLC-AAS, HPLC-ICP-OES, etc.) and surface-enhanced Raman scattering (SERS) techniques (Kodamatani et al., 2011; Hashemi-Moghaddam, Saber-Tehrani, 2008; Guerrini et al., 2014). These approaches share a good reliability, high sensitivity (LoD of 0.14-0.17 ppb) and accuracy discriminating among multiple mercury species (as methylmercury, ethylmercury, phenylmercury and the mercury ions) with extreme precision. However, they have some limitations in terms of lab constrain, referring to the bulky instruments, and time and cost of analysis, considering the reactants and procedure of sample preparation required for the mercury speciation, which make these methods unsuitable for on-site measurements. In this sense, many attempts have been made towards the miniaturization of the entire detection system, as for the sensing platform based on optical (both colorimetric and fluorometric) and electrochemical detection (Santangelo et al., 2014). Optical sensors for the HgII detection in water provide an improvement in terms of time and miniaturization of analysis but are limited by the low sensitivity (most of the colorimetric sensors report a LoD of $10 \mathrm{ppb}$ ) and the risk of cross-sensitivity towards other metal ions (Chen et al., 2015; Yang et al., 2018).

The above reported limitations can be overcome by using quantitative transduction technologies based on electrical signal, as those based on the Anodic Stripping Voltammetry or the Screen-Printed Electrodes, where the measurement of the analyte concentration is not influenced by the size of the sample used (Renedo, Alonso-Lomillo, Martínez, 2007). In this context, the continuous development of electrochemical silicon-based technologies together with miniaturization of biotechnologies can give an opportunity to develop portable 
and easy-to-use sensing devices able to solve the lab constraints above described particularly those related to the need of specialized personnel. The effectiveness of this approach has been already demonstrated in several areas of medical field such us nucleic acids analysis (Petralia, Sosentino, Sinatra et al., 2017; Petralia, Sciuto and Conoci, 2017; Petralia, Sciuto, Di Pietro, et al., 2017) glucose and biomolecules sensing (Petralia et al., 2018). Electrochemical systems share the advantages of a high miniaturization degree, especially for those improved with silicon technology (Petralia, Sciuto, di Pietro et al et al., 2017), and a rapid and highsensitivity analysis. Actually, it has been found in case of AsIII detection reaching a LoD $>1 \mathrm{ppb}$ that is well below the WHO value. However, the sample preparation requires a pre-dilution of real samples before analysis that can introduce additional variability into the measurement and interferences (Toor, Sharma, Bansod, 2015). However, electrochemical systems often require an expensive fabrication, considering the functionalization and electrodes modification, and imply weak sensing elements, as for the enzyme-based sensors (Pujol et al., 2014; Fu et al., 2011).

To overpass these limitations, electrochemical sensors based on Noble Metal nanoparticle-modified electrodes (Pd, Pt, Ag etc.) have been developed for a wide series of applications (Petralia, et al, 2012; Majid et al., 2006). Although they show excellent performances in terms of sensitivity, however few data for specificity are reported (Kumar et al., 2017; Babar et al., 2019). In this context, sensing strategies based on specific enzyme are very appealing since they can offer selective detection. In the case of arsenic direct enzymatic recognition by arsenite oxidase Male et al., 2007) or indirect recognition trough $\beta$-galactosidase have been reported (Stocker et al., 2003), reducing the risk of cross-reactivity and increasing both the sensitivity and selectivity. However, both these technological approaches present some issues related to the specificity of the nanostructures-based sensor and to the costs production and stability of enzyme-based device which degenerate after a long usage inhibiting the recognition activity.

More recently, whole-cell based biosensors received a widespread attention for their properties. Most of them are based on microorganisms, especially bacteria, that have been genetically modified in order to be sensitive towards the specific analyte of interest (Sciuto et al., 2019; Gu, Mitchell, Kim, 2004). These biosensors use engineered bacterium (generally an Escherichia coli) as sensing element that, each time it interacts and internalises the analyte to detect, produces a reporter protein that express a detection signal (optical, electrical and/or electrochemical). The genetic modification of the sensing element makes the whole-cell-based biosensor extremely customizable. Moreover, thanks to its intrinsic properties, the sensing bacterium is physiologically more robust than enzymes, in case of prolonged usage allowing a high degree of miniaturization and portability, due to the small size and the survival at different environmental conditions (Gilchrist et al., 2005). Finally, the genetic recognition of arsenic, based on the modified expression of the ars operon sequences, $\beta$-galactosidase or luciferase gene, guarantees a strong selectivity excluding the risk of cross-reactivity (Gui et al., 2017). However, the biotechnology has the main limitation of the sample management since the sensing bacteria are strictly dependant on the nutrients availability and the environmental parameters ( $\mathrm{pH}$, temperature, or ionic strength) and, usually, require a long time period to complete the genetic recognition of target, from the arsenic internalization to the reporter protein transcription and translation.

In this work we propose an innovative miniaturized electrochemical biosensing platform for the specific and high-sensitive quantification of metal ions in water sample. The sensor system exploits the synergy between two interfaced sensing modules: (a) a whole-cell-based module using an engineered Escherichia coli as wholecell sensing element; (b) an electrochemical module based on a silicon chip, integrating electrochemical cells (EC-cell) composed by three planar microelectrodes, and a portable EC-reader, performing a cyclic voltammetry (CV) analysis. The whole-cell sensing element has been genetically modified to produce a redox active 4-aminophenol, as mediator, each time it interacts with the metal target in a highly specific manner. Thanks to the electrochemical detection of the mediator, the metal is indirectly detected and quantified. Sensitivity, robustness and selectivity of the sensing system have been fully studied for AsIII and preliminary investigated for HgII proving the fully versatility of the system towards multiplex heavy metals detection. 


\section{Experimental section}

Chemicals. ([Os(bpy $\left.)_{2} \mathrm{DPPZ}\right] \mathrm{Cl}_{2}$ ) was prepared according the procedures reported in the work of Petralia, Sciuto, Di Pietro et al (2017). The engineered E. coli strains, specific for AsIII and HgII, the ampicillin antibiotic and the 4-aminophenyl $\beta$-D-galactopyranoside powder were provided by the EEM-Lab of the University of Lausanne and used as described in the section below. Filtered sterile 10X $(1 \mathrm{mM})$ phosphate-buffered saline solution, or PBS, $\left(137 \mathrm{mM} \mathrm{NaCl}, 2.7 \mathrm{mM} \mathrm{KCl}, 4.3 \mathrm{mM} \mathrm{Na}_{2} \mathrm{HPO}_{4}\right.$ and $1.47 \mathrm{mM} \mathrm{KH}_{2} \mathrm{PO}_{4}, \mathrm{pH}=7$, Fisher Scientific) was diluted 10-fold for usage. Sterile Luria Bertani (LB) broth and chloride potassium ( $\mathrm{KCl}$ ) were purchased from Sigma. Sodium arsenite $\left(\mathrm{NaAsO}_{2}\right)$, mercury chloride $\left(\mathrm{HgCl}_{2}\right)$ and cadmium sulphate $\left(\mathrm{CdSO}_{4}\right)$ powders, from Sigma, were dissolved in filtered sterile $1 \mathrm{mM}$ PBS and used for the analysis.

Whole-cell-based module. The whole-cell-based module is represented by the sensing element for the AsIII obtained by the molecular cloning experiment described in the work of Cortés-Salazar et al. (2013).

The sensing element is a genetically modified E. coli strain containing the recombinant plasmid pMV132arsR-ABS in which thears operon promoter sequence $\left(\mathrm{P}_{\text {ars }}\right)$ is fused, downstream, to the ars $\mathrm{R}$ and lac $\mathrm{Z}$ gene.

Electrochemical module. The electrochemical (EC) module of the biosensing system consists of (a) a miniaturized device and (b) a portable electronic system to perform the analysis. The EC device reported in Fig. 1, was manufactured using the VLSI technology on a 6" silicon wafer substrate according to the procedure described in Petralia, Sciuto and Conoci et al., 2017. It is a silicon chip contains 4 EC-cells for multiplexing analysis, each contains three planar microelectrodes so structured: a working electrode (WE) made in platinum, counter and reference electrode (CE, RE) made in gold through sputtering process. Table 1 contains the size of each EC cell. The electrode-to-electrode distances are $100 \mu \mathrm{m}$. The silicon chip is integrated with a polycarbonate ring creating 4 microchambers ( $20 \mu \mathrm{L}$ total volume) and electrically isolated from the substrate by a thermally grown silicon oxide layer (Fig. 1c). The whole device is fixed on a plastic holder for an easily handling. The EC device is connected with a customised board developed by STMicroelectronics acting as miniaturised potentiostat and used to perform the electrical driving of CV measurements on samples (Fig 1b-c).

Experimental procedure for analysis. To prepare the samples for the analysis, the E. coli sensing element was plated $24 \mathrm{~h}$ in LB-agar added with ampicillin $100 \mu \mathrm{g} / \mathrm{ml}$. The day after, few colonies of the plate were suspended in $20 \mathrm{~mL}$ of fresh $\mathrm{LB}$ broth and incubated overnight at $21^{\circ} \mathrm{C}-150 \mathrm{rpm}$. The last $3 \mathrm{~h}$ cells were incubated at $37^{\circ} \mathrm{C}-150 \mathrm{rpm}$ until the optical density $\left(\mathrm{OD}_{600 \mathrm{~nm}}\right)$ was around 0.6. Subsequently, the culture was diluted 2-fold in tap water (final volume of $10 \mathrm{~mL}$ ) and used to prepare the following mixes: $800 \mu \mathrm{L}$ of diluted $E$. coli culture $+100 \mu \mathrm{L}$ of $2.5-5-10-50-100 \mathrm{ppb} \mathrm{NaAsO}_{2}$ (water as zero) +100 $\mu \mathrm{L}$ of $10 \mathrm{mM}$ PAPG. Once induced by incubation at $30^{\circ} \mathrm{C}-350 \mathrm{rpm}-2 \mathrm{~h}, 20 \mu \mathrm{L}$ of the induced mixes have been immediately spotted into the microchambers of the EC device and analyzed by CV. For each concentration, samples have been prepared and measured in triplicate. The experimental procedure was repeated by substituting the $\mathrm{NaAsO}_{2}$ with $\mathrm{HgCl}_{2}(\mathrm{HgII})$ and $\mathrm{CdSO}_{4}(\mathrm{CdII})$ to test the cross-reactivity.

Electrochemical measurements. CV measurements were carried out by using the portable electronic board linked to a laptop via USB connection (Fig. 1C). A RealTerm and MATLAB software were used to manage, respectively, the electronic settings for the $\mathrm{CV}$ experiments and the collection and post-processing of data coming from the board. The experiment was set using a scan rate of $10 \mathrm{mV} / \mathrm{s}$ and a voltage range of -1.5 $\mathrm{V} /+1.5 \mathrm{~V}$, and focusing on the anodic peak of PAP at around $+1.2 \mathrm{~V}$. Before each test, the platinum surface of the $\mathrm{WE}$ was activated by 50 sweeps of $\mathrm{CV}$ in $\mathrm{KCl} 0.1 \mathrm{M}$. The LoD was obtained by measuring 3 replicas of a blank sample and calculating the mean result and the standard deviation (SD) according to the following equation $\mathrm{LoD}=3 \times \mathrm{SD}_{\text {Regression }}$ / Slope, while the Limit of Quantification was calculated by the follows equation $\mathrm{LoQ}=(\mathrm{LoD} / 3) \times 10$. The delta current signal (I delta) was calculated as the difference between the current recorded in whole-cell biosensor in presence of the metal analyte and the current signal with $0 \mathrm{ppm}$ of analyte (blank).

\section{Results and Discussions}


The electrochemical miniaturised silicon chip used in the present study is reported in Fig.1. It integrates four types of layout of EC-cells configured with three planar microelectrodes (WE, CE and CE) featured by different sizes and shapes (Fig 1a). Table 1 reports both the physical dimensions and the eras of each electrode/cell-type. The silicon chip has been integrated with plastic PC ring to create a reaction sampling chamber of $25 \mu \mathrm{L}$ for each EC cell and mounted on a customised electronic board for driving the electrical signals. The final whole portable EC system was connected to PC to automatically managed the reading process (Fig. 1b-c).

The first part of our study was focused on the evaluation of the EC-cells performances of the 4 layouts present in the EC chip. With this purpose, we carried out electrochemical measurements using Osmium based redox probe $\left(\left[\mathrm{Os}(\mathrm{bpy})_{2} \mathrm{DPPZ}\right] \mathrm{Cl}_{2}\right)$ at concentration ranging from $0.1 \mu \mathrm{M}$ to $100 \mu \mathrm{M}$ in $\mathrm{KCl} 20 \mathrm{mM}$. Figure 2 reports the square wave (SW) intensity signals recorded at the oxidation peak of Os complex of 0,76V. The data show that four cells exhibit different performances with current intensities of EC1> EC2> EC4>EC3 (Fig. 2(a)), with a linear behavior in the concentration range of $0-50 \mu \mathrm{M}$ of Os complex (Fig. $2(\mathrm{c}))$. This finding can be correlated with both the area of WE and the WE-CE distance cell parameters. Actually, as it is illustrated in Fig 2 (c) and (d), EC1 cell present the highest WE area and highest WE-CE distance and it has been found to the best performer (Fig 2(a)). In case of EC2, even if it has the same WE area of EC1, however it is featured by a shorter WE-CE distance leading to current intensities lower than EC1. For EC4 and EC3 the worst performances can be correlated to both the lower WE area and the shorter WE-CE distance (both the lowest for EC3). The results were also confirmed using other redox probe, such as $\mathrm{Fe}^{\mathrm{II}}(\mathrm{CN})_{6}$ (data not showed).

Based on the above reported results we selected layout 1 of the EC chip for the heavy metal detection through the whole-cell sensing element using the engineeredEscherichia coli . The principle of the sensing method is schemed in Fig. 3. More in details, thanks to the genetic modification carried out on E. coli, when AsIII metal goes into the bacterium cell, the ArsR protein is released from its DNA binding site (located to the downstream of ars operon promoter sequence $\mathrm{P}_{\text {ars }}$ ) and bind the AsIII metal. This process has been designed taking inspiration to the intrinsic arsenate resistance mechanism of bacteria (Cervantes et al.,1994). When ArsR-AsIII binding event occurs, $\mathrm{P}_{\text {ars }}$ is free to increase the expression level oflac $\mathrm{Z}$ gene, resulting in the synthesis of $\beta$-galactosidase (Stocker et al., 2003; Cortés-Salazar et al., 2013). The enzyme, then, cleaves the 4-aminophenyl $\beta$-D-galactopyranoside (PAPG) and produces the 4-aminophenol (PAP). Once released by the $E$. coli cells, PAP interacts with the WE inside the EC device and trig a redox exchange producing a current signal that is, then, detected and quantified by CV analysis to give the final output. Depending on the amount of AsIII present in the sample, E. coli produces a correspondent concentration of PAP that is electrochemically detected. Fig. 4(a) reports CV results obtained by using concentration of AsIII from 0 to 100ppb. As shown, PAP oxidation peaks are centred from $+1.0 \mathrm{~V}$ to $+1.2 \mathrm{~V}$. By going from the lowest concentration of $2.5 \mathrm{ppb}$ (red line) up to the highest $100 \mathrm{ppb}$ (orange line) the peak intensities increased over the background (0 ppb sample) (blue dashed arrow). It can be observed a voltage shifts of the PAP oxidation peak as illustrated in the inset of Fig. 4(a) (green dashed arrow). Theses shifts correspond to $+50 \mathrm{mV}$ for $2.5 \mathrm{ppb},+150 \mathrm{mV}$ for $10 \mathrm{ppb},+300 \mathrm{mV}$ for $50 \mathrm{ppb}$ and $+350 \mathrm{mV}$ for $100 \mathrm{ppb}$. They can be explained by the gradual adsorption of the redox product of PAP over the platinum surface of WE, affecting the electrolytic process (Chandrashekar et al., 2011; Wudarska et al., 2015; Salavagione et al., 2004; Amanullah et al., 2010).

It can be also observed that the E. coli strain exhibit a proper broad peak at about $1 \mathrm{~V}$ (Fig. 4(a) curve 0 $\mathrm{ppb})$. This is probably lead to the biological matrix of the cellular line. The reduction peak for dissolved oxygen was observed in the range- $0.5 \mathrm{~V}-1.1 \mathrm{~V}$.

The analysis of CV signal intensities is reported in Fig. 4(b-c). Data showed a linear current increase of PAP peaks when AsIII concentration is from $2.5 \mathrm{ppb}$ to $50 \mathrm{ppb}$ and a slope change from $50 \mathrm{ppb}$ to $100 \mathrm{ppb}$ (Fig. 4(b)). It is noteworthy that the sensor shows a detectable signal at 2.5ppb of AsIII metal below the WHO threshold (10 ppb).

The linear trend was deeper investigated using AsIII concentrations of $2.5 \mathrm{ppb}, 5 \mathrm{ppb}, 10 \mathrm{ppb}$ and $50 \mathrm{ppb}$. The current intensities of CV curves as function of the AsIII concentration are plotted and linearly interpolated 
in Fig. 4(c). The analysis of the curve show sensitivity of $0.122 \mu \mathrm{Appb}^{-1} \mathrm{LoD}$ of $1.5 \mathrm{ppb}$ and a LoQ of 5 ppb. These values are lower than the acceptable limit of arsenite in water as defined by the WHO (LoD 10 $\mathrm{ppb}$ ), suggesting the possibility to quantify the pollutant amount already before its dangerous accumulation in water. It is noteworthy that, compared to our previous system using the whole-cell detection for AsIII (Cortés-Salazar et al., 2013), the proposed platform has a sensitivity about 40 times higher $(0.12 \mu \mathrm{A} / \mathrm{ppb}$ versus $0.0028 \mu \mathrm{A} / \mathrm{ppb}$ ). This finding could be reasonable explained by best performance of our silicon-based EC-cells which planar electrodes assured a higher current intensity signal, as confirmed by the comparison of the intensity current values recorded by two systems. In particular water samples containing AsIII in concentration $10 \mathrm{ppb}$, interrogated with the proposed platform gives a current intensity value of $1.5 \mu \mathrm{A}$ while the previous system gives a very low current value of $55 \mathrm{nA}$. It is noteworthy, this highly sensitive integrated detection was obtained without any additional reagent consumption, since the enzyme is directly produced by the sensing cells, giving an extreme precise quantification of AsIII in a small sample of water (just $20 \mu \mathrm{L}$ ), with a linear trend revealed at low concentration range, well below the $10 \mathrm{ppb}$ guideline value.

The selectivity of the miniaturized biosensor was studied by testing the whole AsIII- $E$. coli cell portable sensor towards HgII and CdII metals. Results are summarised in Fig. 5. When HgII and CdII metals are present in the sampling water solution, no PAP signals were detected at in the range $+1.0 \mathrm{~V}-1.2 \mathrm{~V}$, while the reduction peaks for dissolved oxygen were still present the range-0.5 V -1.1 V (Fig $5(\mathrm{a}-\mathrm{b})$ ). Figure $5 \mathrm{c}$ reports the plots of the delta currents of both HgII (red line) and CdII (blue line) compared with those showed by AsIII (green line; data extracted from Fig 4b). The results confirm the specific genetic recognition operating inside the E. coli cells with the activity of Pars promoter enhanced only the by AsIII species inducing the arsR-mediated expression of $\beta$-galactosidase and the production and release of the PAP redox mediator. The selectivity is guaranteed without the need of any chemical reagent and enzymatic or nanostructural functionalizations, that can degenerate after long usages and affect the quality and cost of screening.

In order to assess the multiplex capability of our portable platform, we also included an additional test using a genetically modified E. Coli strain specific for the HgII species. This strain was modified in order to trig the $\beta$-galactosidase expression, thus the PAP production, once interacted with HgII species revealed in water. We preliminary investigated this assay using the following amount of HgII: 0, 0.25ppb, 1ppb, 2.5ppb and 10 ppb. The recorded I delta currents values are plotted in fig. 6(a). A linerar behaviour was observed in the range $0-2.5 \mathrm{ppb}$ luading to a sensitivity value of $2.1 \mu \mathrm{A} / \mathrm{ppb}$, LOD value of $0.1 \mathrm{ppb}$ and LoQ value of 0.34 ppb (inset of Fig 5a). These starting data are optimal considering the 1ppb WHO tolerance value for total $\mathrm{HgII}$ in water. A good specificity was also observed since no signal was recorded in presence of unspecific AsIII and Cd II species (Fig 6(A)).

Optimization tests are in progress to improve the sensing performances of the system towards HgII species.

\section{Conclusions}

In this work we propose an innovative miniaturized electrochemical biosensing platform for the specific and high-sensitive quantification of metal ions in water sample. The platform synergically interface a biosensing module based on whole-cell using engineered Escherichia coli and a miniaturised electrochemical silicon chip integrating 4 type of EC cells configured with three planar microelectrodes and a portable EC-reader. The electrochemical characterization of the silicon chip using Os complex redox probe show that that EC1 cell show the best EC performances in terms of current intensity respect to the other ECs configuration (EC2-EC4). This was attributed to the highest WE area and WE-CE distance of EC1 that was chosen for the sensing test towards the heavy metals. The sensing mechanism relies on the selective recognition from a specific engineered $E$. coli towards a given metals producing the 4-aminophenol (PAP) redox active mediator detected through a cyclic voltammetry analysis. The miniaturized biosensor is able to operate a portable, robust and high-sensitivity detection showing for AsIII a sensitivity of $0.122 \mu \mathrm{A}$ ppb-1, LoD of 1.5 $\mathrm{ppb}$ and a LoQ of $5 \mathrm{ppb}$. It is noteworthy that the LoD value is one order of magnitude below of the value indicated to $\mathrm{WHO}$ to be dangerous $(10 \mu \mathrm{g} / \mathrm{L})$. The system was proved to be fully versatile being effective in the detection of $\mathrm{Hg}$ (II) as well. A preliminary study on $\mathrm{Hg}(\mathrm{II})$ showed sensitivity value of $2.11 \mu \mathrm{A} / \mathrm{ppb}$ a LOD value of $0.1 \mathrm{ppb}$ and LoQ value of $0.34 \mathrm{ppb}$. Also in this case, the detected LOD was ten time lower 
than that indicated by WHO (1 ppb).

The platform miniaturization together with the limited fluidic movement make of the proposed assay a potential portable and easy-to-use system for unspecialized personnel for outdoor application. These results pave the way for advanced sensing strategies suitable for the environmental monitoring and the public safety.

\section{References}

Amanullah, A., Otero, J.M., Mikola, M., Hsu, A., Zhang, J., Aunins, J., Schreyer, H.B., Hope, J.A. \& Russo, A.P. (2010). Novel micro-bioreactor high throughput technology for cell culture process development: Reproducibility and scalability assessment of fed-batch CHO cultures.Biotechnology and Bioengineering, 106, 57-67. https://doi.org/10.1002/bit.22664.

Babar, N., Joya, K. S., Tayyab, M. A., Ashiq, M. N., \& Sohail, M. (2019). Highly Sensitive and Selective Detection of Arsenic Using Electrogenerated Nanotextured Gold Assemblage. ACS Omega, 4 (9), 1364513657. https://doi.org/10.1021/acsomega.9b00807.

Bose, U., Rahman, M., \& Alamgir, M. (2011). Arsenic Toxicity and Speciation Analysis in Ground Water Samples: A Review of Some Techniques. International Journal of Chemical Technology, 3, 14-25. DOI: 10.3923/ijct.2011.14.25. http://dx.doi.org/10.3923/ijct.2011.14.25.

Cervantes, C., Guangyong, J., Ramírez, J.L., \& Silver, S. (1994). Resistance to arsenic compounds in microorganisms. FEMS Microbiology Reviews, 5 (4):355-67. https://doi.org/10.1111/j.1574-6976.1994.tb00145.x.

Chandrashekar, B.N., Swamy, K., Pandurangachar, M., Sathisha, T., \& Sherigara, B. (2011). Electrochemical Investigation of 4-Aminophenol at CTAB Modified Carbon Paste Electrode: A Cyclic Voltammetric. Anal. Bioanal. Electrochem., 3 , 227-232. https://doi.org/10.3390/s140508926.

Chen, K., She, S., Zhang, J., Bayaguud, A., \& Wei, Y. (2015). Label-free colorimetric detection of mercury via $\mathrm{Hg} 2+$ ions-accelerated structural transformation of nanoscale metal-oxo clusters. Sci. Rep., 5, 16316.

Cortés-Salazar, F., Beggah, S., van der Meer, J.R., \& Girault, H.H. (2013). Electrochemical As(III) whole-cell based biochip sensor.Biosensors $\& 3$ Bioelectronics, 47 , 237-242. https://doi.org/10.1038/srep16316.

Fu, X.C., Chen, X., Guo, Z., Xie, C.G., Kong, L.T., Liu, J.H., \& Huang, X.J. (2011). Stripping voltammetric detection of mercury(II) based on a surface ion imprinting strategy in electropolymerized microporous poly(2-mercaptobenzothiazole) films modified glassy carbon electrode.Anal. Chim. Acta, 685 , 21-28. https://doi.org/10.1016/j.aca.2010.11.020.

Gilchrist, K.H., Giovangrandi, L., Whittington, R.H., \& Kovacs, G.T. (2005). Sensitivity of cellbased biosensors to environmental variables.Biosensors $\&$ Bioelectronics, 20 , 1397-1406. https://doi.org/10.1016/j.bios.2004.06.007.

Gu, M.B., Mitchell, R.J., \& Kim, B.C. (2004). Whole-cell-based biosensors for environmental biomonitoring and application.Advances in Biochemical Engineering/Biotechnology, 87 , 269-305. https://doi.org/10.1007/b13533.

Guerrini, L., Rodriguez-Loureiro, I., Correa-Duarte, M.A., Lee, Y.H., Ling, X.Y., García de Abajo, F.J, \& Alvarez-Puebla, R.A. (2014). Chemical speciation of heavy metals by surface-enhanced Raman scattering spectroscopy: Identification and quantification of inorganic- and methyl-mercury in water. Nanoscale, 6, 8368-8375. https://doi.org/10.1039/c4nr01464b.

Gui, Q., Lawson, T., Shan, S., Yan, L. \& Liu, Y. (2017). The Application of Whole Cell-Based Biosensors for Use in Environmental Analysis and in Medical Diagnostics. Sensors, 17, 1623. https://doi.org/10.3390/s17071623.

Hashemi-Moghaddam, H., \& Saber-Tehrani, M. (2008). Sensitive mercury speciation by reversed phase column high-performance liquid chromatography with UV-visible detection after solid-phase extraction using 6-mercaptopurine and dithizone. J. AOAC Int., 6,1453-1458. https://doi.org/10.1093/jaoac/91.6.1453. 
Kodamatani, H., Kanzaki, R., Tomiyasu, T., Saito, K., \& Kono, Y. (2011). Determination of organic and inorganic mercury species as emetine dithiocarbamate complexes by high-performance liquid chromatography with electrogenerated tris(2,20-bipyridine) ruthenium(iii) chemiluminescence detection. Anal. Lett., 44 , 2769-2779. https://doi.org/10.1080/00032719.2011.565442.

Kumar, S., Deep, A., Kim, K., Kailasa, S., \& Yoon, H. (2017). Nanomaterial-based electrochemical sensors for arsenic - A review.Biosensors \&3 Bioelectronics, 95 . https://doi.org/10.1016/j.bios.2017.04.013.

Lace, A., Ryan, D., Bowkett, M., \& Cleary, J. (2019). Arsenic Monitoring in Water by Colorimetry Using an Optimized Leucomalachite Green Method. Molecules, 24, 339. https://doi.org/10.3390/molecules24020339.

Li, J., Zheng, B., Zheng, Z., Li, Y., \& Wang, J. (2020). Highly sensitive and selective colorimetric and SERS dual-mode detection of arsenic(III) based on glutathione functionalized Gold nanoparticles.Sens. Actuators Reports, 2 ,100013. https://doi.org/10.1016/j.snr.2020.100013.

Majid, E., Hrapovic, S., Liu, Y., Male, K., \& Luong, J. (2006). Electrochemical Determination of Arsenite Using a Gold Nanoparticle Modified Glassy Carbon Electrode and Flow Analysis. Analytical chemistry, 78 , 762-9. https://doi.org/10.1021/ac0513562.

Male, K. B., Hrapovic, S., Santini, J. M., \& Luong, J. H. T. (2007). Biosensor for Arsenite Using Arsenite Oxidase and Multiwalled Carbon Nanotube Modified Electrodes. Analytical Chemistry, 79 (20), 7831-7837. https://doi.org/10.1021/ac070766i.

Martinez, A. W., Phillips, S. T., Whitesides, G. M., \& Carrilho, E. (2010). Diagnostics for the Developing World: Microfluidic Paper-Based Analytical Devices. Analytical Chemistry , 82 , 3-10. https://doi.org/10.1021/ac9013989.

Morita, K., \& Kaneko, E. (2006). Spectrophotometric determination of trace arsenic in water samples using a nanoparticle of ethyl violet with a molybdate-iodine tetrachloride complex as a probe for molybdoarsenate,Anal. Sci., 22 , 1085-1089. https://doi.org/10.1021/ac061074h.

Petralia, S., Barbuzzi, T., \& Ventimiglia, G. (2012). Polymerase chain reaction efficiency improved by water soluble $\beta$-cyclodextrins capped platinum nanoparticles. Materials Science and Engineering: C, 32(4), 848850. https://doi.org/10.1016/j.msec.2012.01.036.

Petralia, S., \& Conoci, S. (2017). PCR technologies for point of care testing: Progress and perspectives, ACS Sensors, 2, 7 876-891. https://doi.org/10.1021/acssensors.7b00299.

Petralia, S., Cosentino, T., Sinatra, F., Favetta, M., Fiorenza, P., Bongiorno, C., Sciuto, E.L., Conoci, S., \& Libertino, S. (2017). Silicon Nitride Surfaces as Active Substrate for Electrical DNA Biosensors. Sensors and Actuators B: Chemical, 252,https://doi.org/10.1016/j.snb.2017.06.023.

Petralia, S., Sciuto, E.L., \& Conoci, S. (2017). A novel miniaturized biofilter based on silicon micropillars for nucleic acid extraction.Analyst, 142 , 1, 140 -146. https://doi.org/10.1039/C6AN02049F.

Petralia, S., Sciuto, E.L., Di Pietro, M.L., Zimbone, M., Grimaldi, M.G., \& Conoci, S. (2017). An innovative chemical strategy for PCR-free genetic detection of pathogens by an integrated electrochemical biosensor. Analyst, 142, 12, 2090-2093. https://doi.org/10.1039/C7AN00202E.

Petralia, S., Sciuto, E.L., Messina, M., Scandurra, A., Mirabella, S., Priolo, F., \& Conoci, S. (2018). Miniaturized and Multi-Purpose Electrochemical Sensing Device based on thin Ni Oxides. Sensors and Actuators B: Chemical, 263 , 10-19. https://doi.org/10.1016/j.snb.2018.02.114.

Pujol, L., Evrard, D., Groenen-Serrano, K., Freyssinier, M., Ruffien-Cizsak, A., \& Gros, P. (2014). Electrochemical sensors and devices for heavy metals assay in water: The French groups' contribution. Front. Chem., 2 , 1-24. https://doi.org/10.3389/fchem.2014.00019.

Renedo, O. D., Alonso-Lomillo, M. A., \& Martínez, M. J. A. (2007). Recent developments in 
the field of screen-printed electrodes and their related applications. Talanta, 73, 202-219. https://doi.org/10.1016/j.talanta.2007.03.050.

Salavagione, H. J., Arias, J., Garcés, P., Morallón, E., Barbero, C., \& Vázquez, J. L. (2004). Spectroelectrochemical study of the oxidation of aminophenols on platinum electrode in acid medium. J. Electroanal. Chem., 265, 375-383. https://doi.org/10.1016/j.jelechem.2003.11.005.

Santangelo, M.F., Sanfilippo, D., Fallica, G., Busacca, A. C., Pagano, R., Sciuto, E. L., Lombardo, S., \& Libertino, S. (2014). SiPM as novel optical biosensor transduction and applications. Fotonica AEIT Italian Conference on Photonics Technologies , 1-4. https://doi.org/10.1109/Fotonica.2014.6843944.

Sciuto, E.L., Coniglio, M.A., Corso, D., van der Meer, J.R., Acerbi, F., Gola, A. \& Libertino, S. (2019). Biosensors in Monitoring Water Quality and Safety: An Example of a Miniaturizable Whole-Cell Based Sensor for Hg2+ Optical Detection in Water. Water, 11, 1986. https://doi.org/10.3390/w11101986.

Stocker, J., Balluch, D., Gsell, M., Harms, H., Feliciano, J., Daunert, S., Malik, K. A., \& Van der Meer, J. R. (2003). Development of a set of simple bacterial biosensors for quantitative and rapid measurements of arsenite and arsenate in potable water. Environmental Science and Technology, 37 (20), 4743-4750. https://doi.org/10.1021/es034258b.

Valli, L., Casilli, S., Giotta, L., Pignataro, B., Conoci, S., Borovkov, V.V., Inoue, Y., \& Sortino, S. (2006). Ethane-Bridged Zinc Porphyrin Dimers in Langmuir-Shafer Thin Films: Structural and Spectroscopic Properties. Journal of Physical Chemistry B, 110, 4691-4698. https://doi.org/10.1021/jp054974v.

Wudarska, E., Chrzescijanska, E., Kusmierek, E., \& Rynkowski, J. (2015). Voltammetric study of the behaviour of N-acetyl-p-aminophenol in aqueous solutions at a platinum electrode. C. R. Chim., 18, 9931000. https://doi.org/10.1016/j.crci.2015.06.017.

Yang, P.C., Wu, T., \& Lin, Y.W. (2018). Label-Free Colorimetric Detection of Mercury (II) Ions Based on Gold Nanocatalysis.Sensors (Basel), 18 , 2807. https://dx.doi.org/10.3390\%2Fs18092807.

World Health Organization (2018, February 15). Arsenic . Retrieved from https://www.who.int/newsroom/fact-sheets/detail/arsenic.

Agency for Toxic Substances and Disease Registry - ATSDR (2007, August). Toxicological Profile for Arsenic . Retrieved from https://www.atsdr.cdc.gov/toxprofiles/tp.asp?id=22\&tid=3.

Hong, Y.S., Song, K.H., \& Chung, J.Y. (2014). Health effects of chronic arsenic exposure. Journal of preventive medicine and public health, 47 (5), 245-252. https://doi.org/10.3961/jpmph.14.035.

Mandal, B.K., \& Suzuki, K.T. (2002). Arsenic round the world: a review.Talanta, 58 , 201-235. https://doi.org/10.1016/S0039-9140(02)00268-0.

Masindi, V., \& Muedi, K.L. (2018). Environmental contamination by heavy metals. In: Saleh, Hosam El-Din M, Aglan, Refaat Fekry Eid Sayed (Eds.), Heavy Metals, Intech Open, U.K, 115-133. https://doi.org/10.5772/intechopen.76082.

Ravenscroft, P., Brammer, H., Richards, \& Wiley-Blackwell, K. (2009).Arsenic Pollution: A Global Synthesis. RGS-IBG Book Series, 1. https://doi.org/10.1002/9781444308785.

Toor, S., Sharma, P., \& Bansod, B. (2015). Electrochemical Detection of Trace Amount of Arsenic (III) at Glassy Carbon Electrode Modified with Au/Fe3O4 Nanocomposites. Aquatic Procedia, 4, 1107-1113. https://doi.org/10.1016/j.aqpro.2015.02.140.

United States Environmental Protection Agency Office of Water (1999).Analytical Methods Support Document for Arsenic In Drinking Water, vol. 22027. Retrieved from https://www.epa.gov.

Verma, R., \& Dwivedi, P. (2013). Heavy metal water pollution-A case study. Recent Res. Sci. Technol., 5 , 98-99. http://dx.doi.org/10.3390/w10111507. 
Yogaraja, N., and Tsai, S.S.H. (2015). Detection of trace arsenic in drinking water: challenges and opportunities for microfluidics.Environmental Science: Water Research \& Technology, 1 , 426-447. https://doi.org/10.1039/C5EW00099H.

Yu, Y.L., \& Wang, J.H. (2013). Recent advances in flow-based sample pretreatment for the determination of metal species by atomic spectrometry. Chinese Science Bulletin, 58 , 1992-2002. https://doi.org/10.1007/s11434-013-5666-9.

\section{Figure Legends}

Figure 1. (a) Miniaturised electrochemical silicon chip integrating 4 layout of EC cells with three planar microelectrodes made in $\mathrm{Pt}(\mathrm{WE})$ and $\mathrm{Au}(\mathrm{CE}$ and $\mathrm{RE}$ ). Table 2 reports the electrodes dimensions; (b) whole portable system EC-reader connected to the PC; (c) details of the portable system EC-reader: electrochemical silicon chip connected to the reading board

Figure 2. (a) Electrochemical response (SW current intensities) of EC-Cells at various Os redox probe amount; (b) linear interpolation of current intensities versus Os amount; (c) Correlation of Sensitivity/WE area; (d) Correlation of Sensitivity/WE-CE distance. The error bars represent the standard deviation from a triplicate.

Figure 3. (a) Details of the EC cell used for the sensing; (b) Principle of the biochemical method based on whole-cell sensing using the engineered $E$. colias sensing element.

Figure 4. (a) CV curves of arsenic sensitive E. coli strain in presence of AsIII at 0 (black line), 2.5ppb (red line), 10ppb (blue line), $50 \mathrm{ppb}$ (green line) and $100 \mathrm{ppb}$ (orange line) and relative current increase (blue dashed arrow). Inset: detail of PAP peak voltage shift (green dashed arrow); (b) CV trend for E. coli samples induced by AsIII in water; (c) calibration curve calculated at $2.5 \mathrm{ppb}$ to $50 \mathrm{ppb}$ of AsIII. The error bars represent the standard deviation from a triplicate.

Figure 5. (a) CV curves of E. coli cells in presence of $\mathrm{HgII}$ at 0 (black line), 2.5ppb (red line), 5 ppb (yellow line), 10ppb (blue line) and $50 \mathrm{ppb}$ (green line); (b) CV curves of E. coli cells in presence of CdII at 0 (black line), 2.5ppb (red line), $5 \mathrm{ppb}$ (yellow line), 10ppb (blue line) and $50 \mathrm{ppb}$ (green line); (c) comparison of PAP current values measured on E. coli samples (specific for AsIII) treated with different concentration of AsIII (green line), HgII (red line) and CdII (blue line). The error bars represent the standard deviation from a triplicate.

Figure 6. (a) CV trend of mercury sensitive E. coli strains induced by $0.25 \mathrm{ppb} ; 1 \mathrm{ppb} ; 2.5 \mathrm{ppb} ; 10 \mathrm{ppb}$ $\mathrm{HgII}$ in water: the insert shows a calibration curve calculated for the low range concentration $(0.25 \mathrm{ppb}$ to $2.5 \mathrm{ppb}$ ) of $\mathrm{HgII}$ in water. (b) comparison of PAP current values measured on E. coli samples (specific for HgII) treated with different concentration of AsIII (green line), HgII (red line) and CdII (blue line). The error bars represent the standard deviation from a triplicate. 


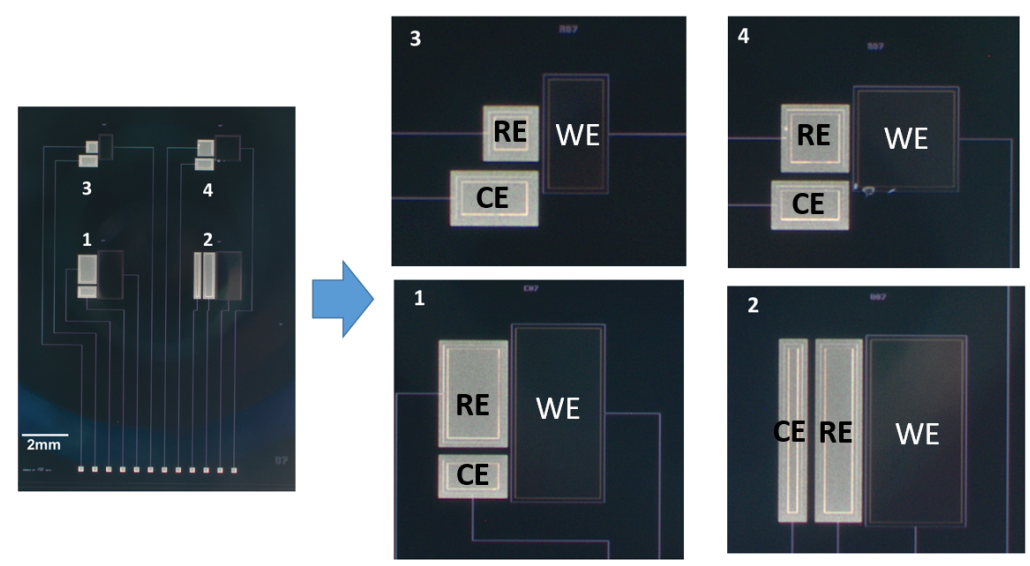

(a)

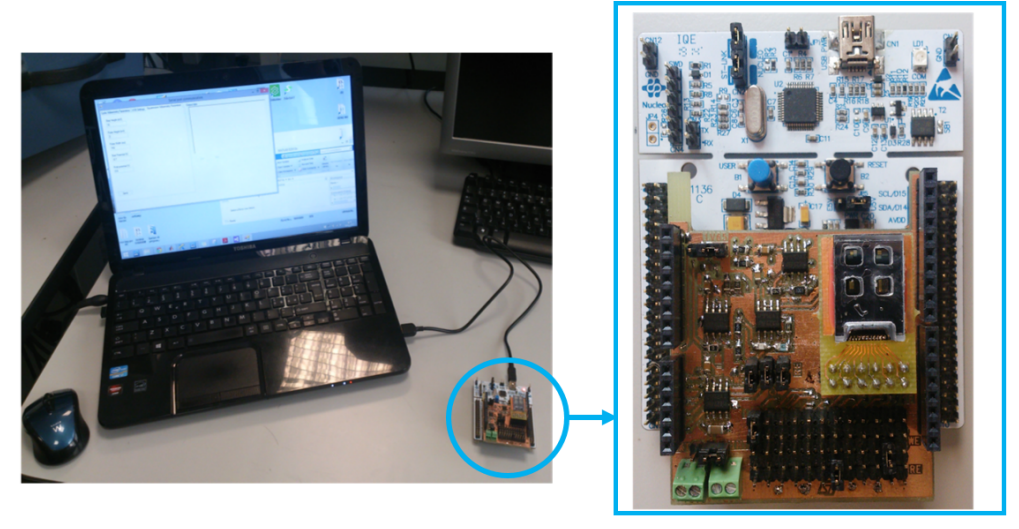

(b)

(c)

\section{Hosted file}

Table.docx available at https://authorea.com/users/300372/articles/482183-miniaturizedelectrochemical-biosensor-based-on-whole-cell-for-heavy-metal-ions-detection-in-water 


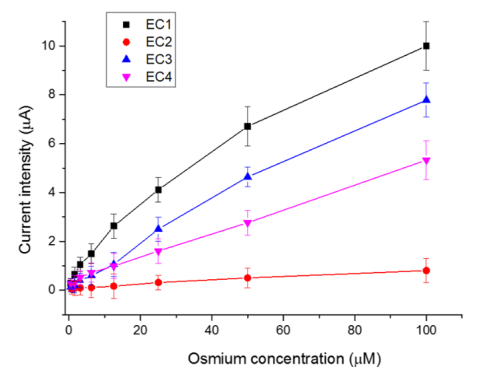

(a)

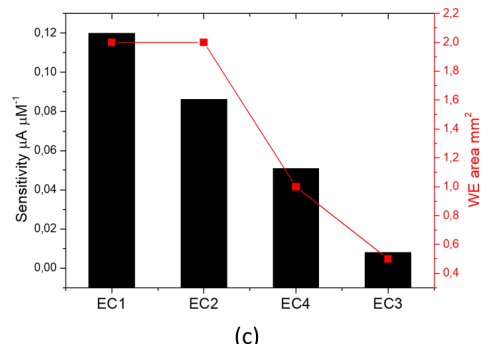

(c)

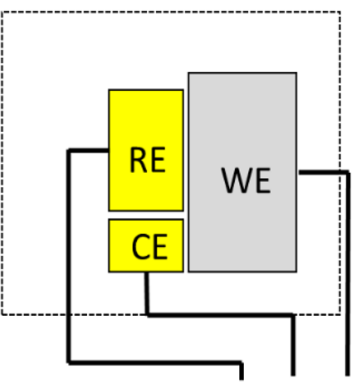

(a)

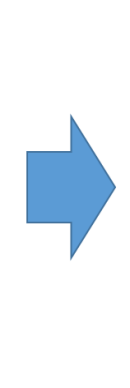

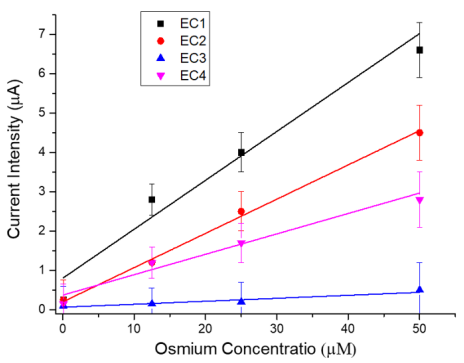

(b)

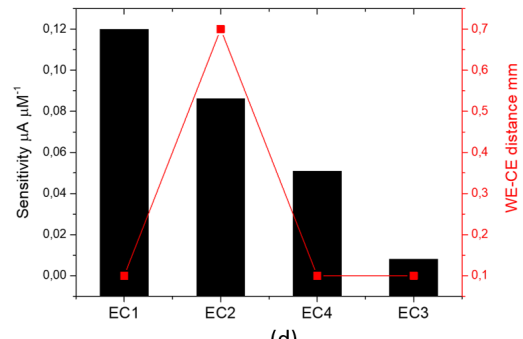

(d)

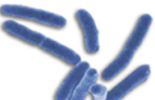

coli

$+\mathrm{As}$ (III)

(b)

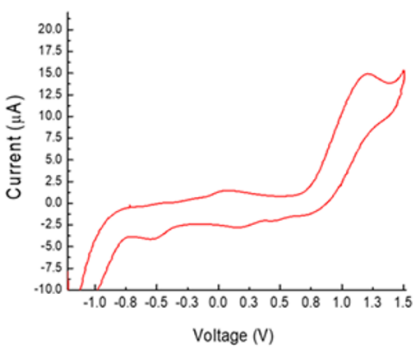

(c) 


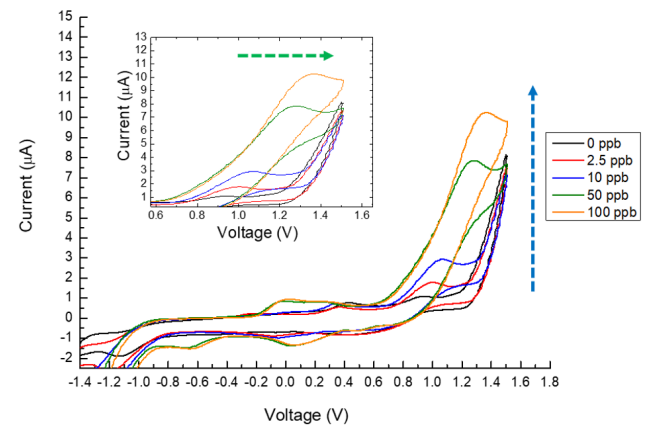

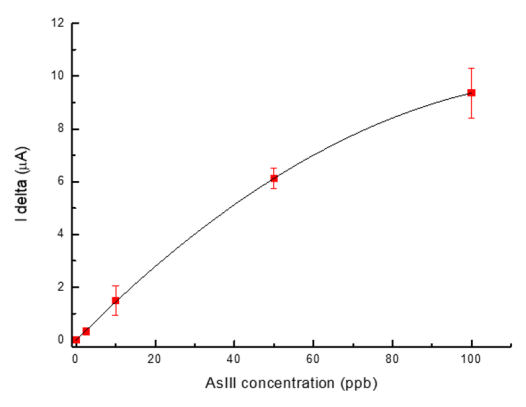

(b)

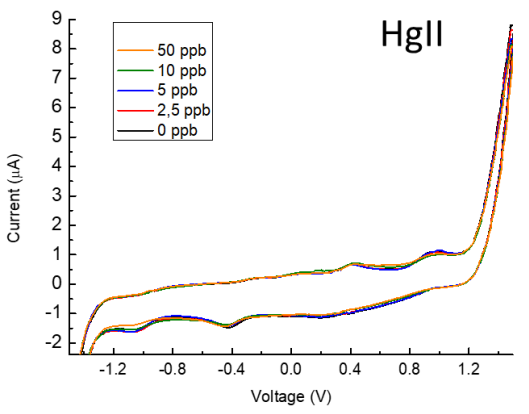

(a)

(a)

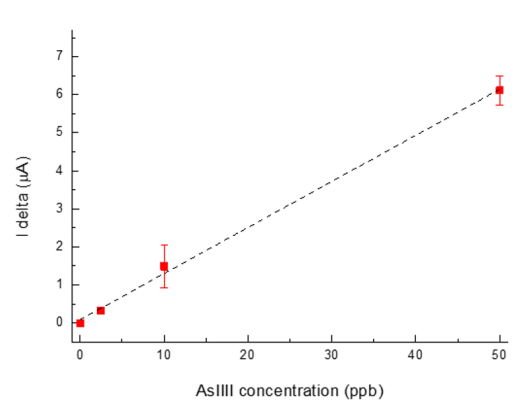

(c)

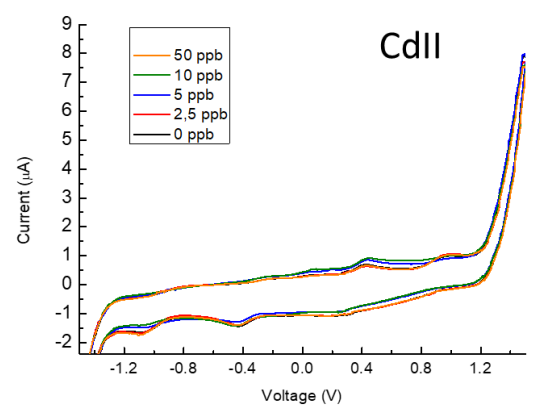

(b)

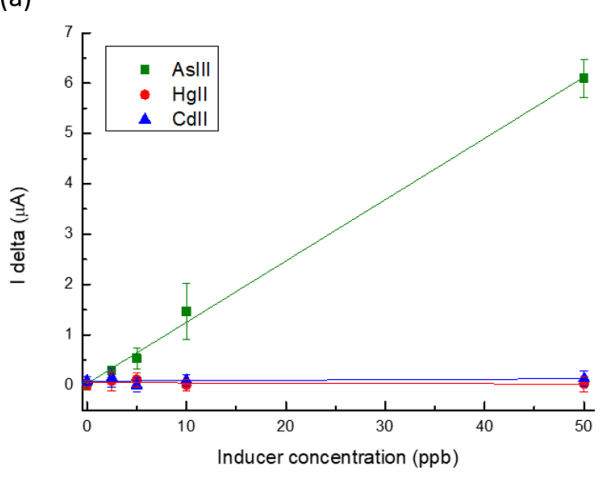

(c) 

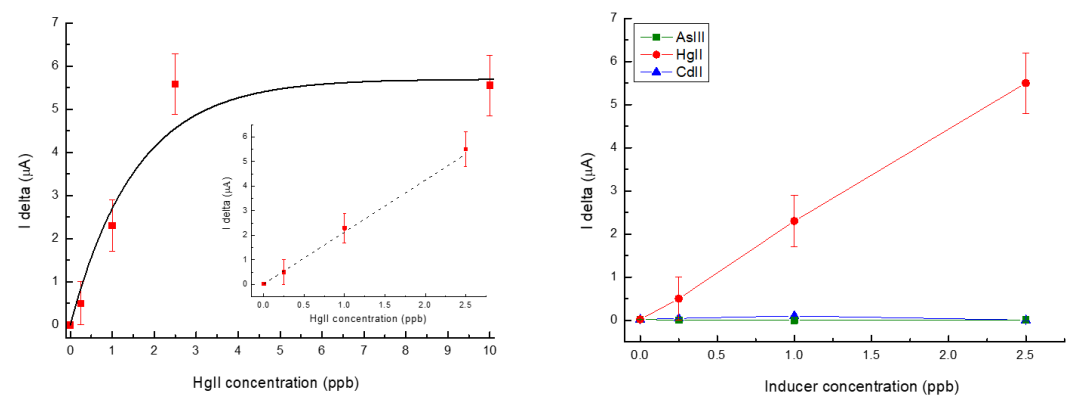